20

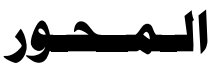

الدراها الحركية والموسيقية في المذهج المطور.

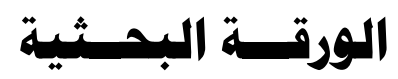

- أساليب توظيف الدراها الموسيقية في رياض الأطفال.

- تنسية ههارات التفكير الإبداعي .

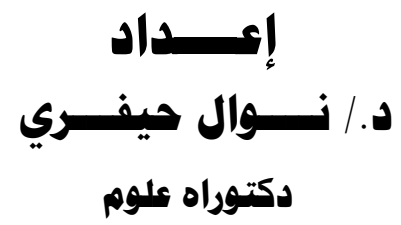

جاهعة هستغانم عبد الصميد بن باديس - الجزائر

لقد كثر الحديث عن أهمية الدراما اعتبارا من أنها أسلوب للتعلم و أن كل ما يقوم به الطفل في الروضة عبارة عن لعب يؤدى إلي الملاحظة والاستتناج

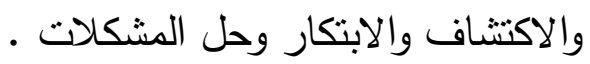

والمقصود باتخاذ المسرح والموسيقى أسلوبا للتعلم والتعليم عندما يستغل هذا النشاط الفطري للطفل في تحقيق أهداف المنهج في جميع مراحل النمو؛ فمن خلال الدراما الموسيقية التعليمية يجمع الطفل معلوماته ويعالجها ويكتسب مهارات عقلية جديدة وهو يمارس مهارات سبق لله اكتسابها. وفي إطار التفاعل تتمو قدرة الطفل علي فهم الرموز واستغلالها في ابتكار رموز وعلاقات يوظفها في فهمه المتتامي لطبيعة الأثياء، أي أن للعب وظيفة

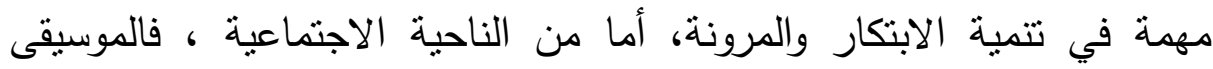
تساعد الطفل على فهم وتجريب أدوار اجتماعية مختلفة . 


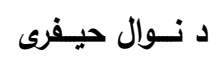

وهناك التنثيل الحركي الذي يقوم بدور هام في تتمية مهارات الطفل الجسمية والحركية، عدا ما يقدمه من فرص للتخلص من القلق والتوتر والتعبير فئري

$$
\text { عن المشاعر بأنواعها. }
$$

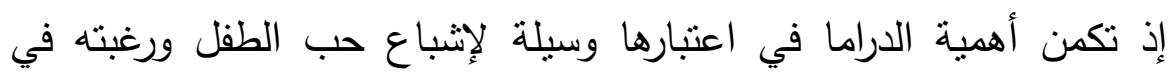

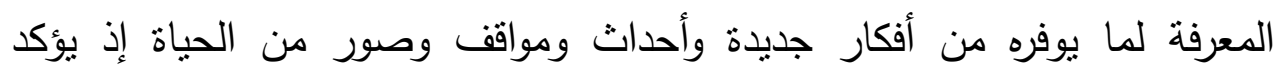
مارك توين Mark Twain عن أهمية ظهور مسرح الأطفال والاهتمام المتعاظم

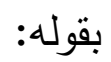

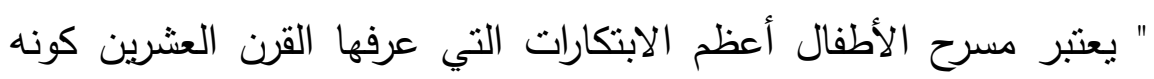

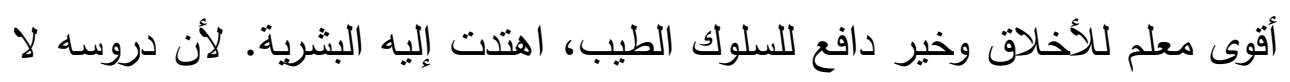

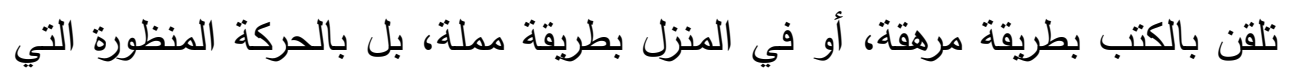

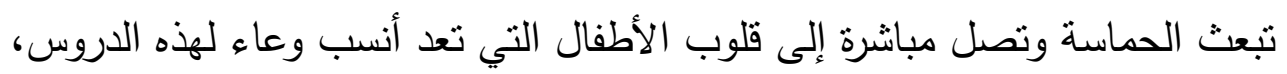

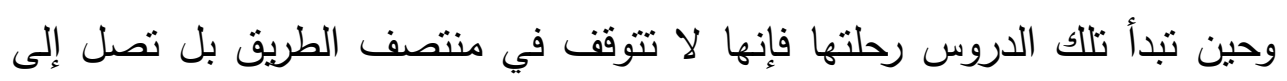

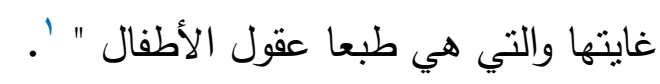

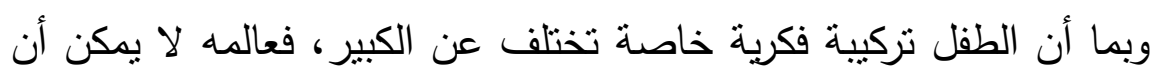
يكون ثابتا وفكره متمركز حول ذاته بمقدار ما يتصور الحياة لعبة يختار أثنياءها

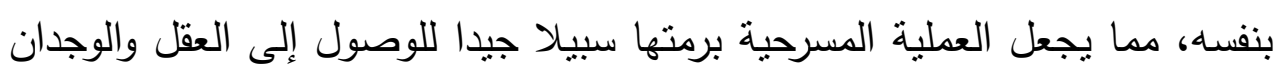

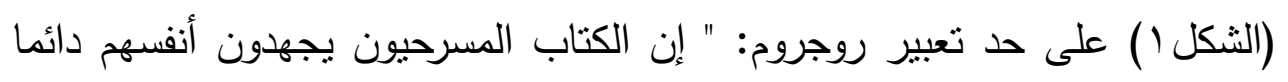

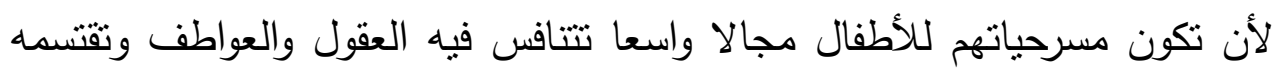

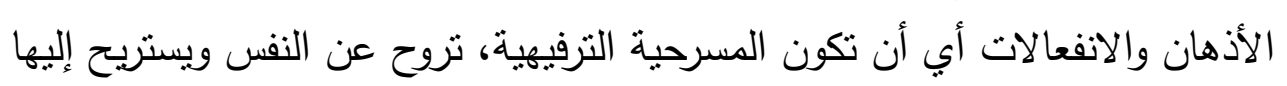

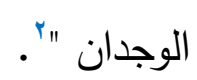

فالدراما أساسا مصدر إثارة وانتباه الطفل ونتويقه لها فيها من تعدد الشخصيات وترقب الأحداث والمسرحيات وتنسلسها، مع خلق الرغبة في الممارسة

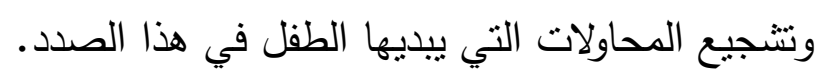

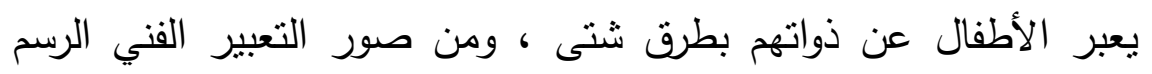

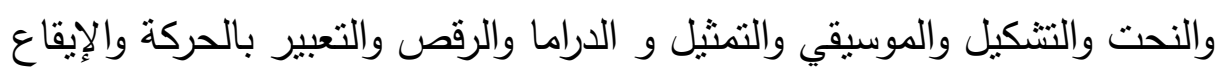




\section{العدد الثالث}

بالإضافة إلي لغة الغناء والشعر ، ويتميز تعبير الطفل في مرحلة ما قبل

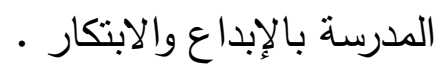

إذ تحقق الدراما الموسيقية أهداف عديدة: لإبنار - تقمية الخيال والإبداع والابتكار - - إتاحة الفرصة للطفل للتعبير عن انفعالاته وأحاسيسه - - التعرف علي خواص الخامات الفنية المختلفة.

فالتعبير بالحركة والموسيقي في مرحلة الطفولة أنسب مرحلة لتتمية مهارات الطفل

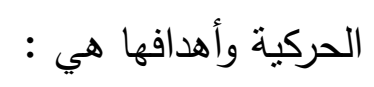
- - إكساب الأطفال المهارات الحركية منل التوازن والتآزر وإصابة الهدف. - - تقوية أجهزة الجسم المختلفة.

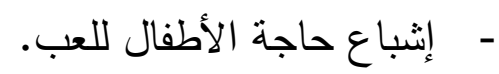
- تهذيب الخلق من خلال المنافسة في اللعب والحركة. - خلق الابداع في التعبير الحركي. - - تعويد الأطفال النظام وإثباع حاجاتهم للقيادة تارة وللتبعية تارة أخرى. وهنا يكمن دور المربيات والمعلمات في جعل النشاط الحركي والموسيقى للطفل خبرة متكاملة تتمي مفاهيمه ومدركاته ومهارته. وعليه " ... يمكن أن تكون طريقة في التعلم لا تقدر بثمن، حيث ومهاته أنها تناعد في كل مناحي تطوير القراءة والكتابة. ومن خلا تطوير الأطفال في مجالات تقسير المعرفة، والطلاقة، والمفردات، والنحو والصرف، والمحادثة، والتحول الإدراكي

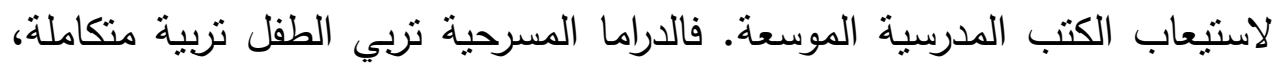
وتوفر لهم الكثير من الحرية، وهامشا من المرونة من خلاله ينمو ويتعلم " ". (الثكل (r) ( ) 

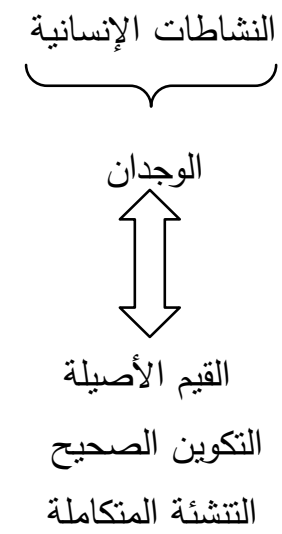

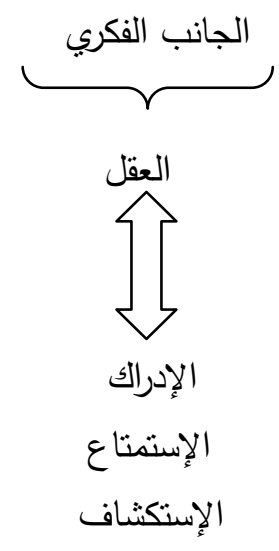

ذلك أن الطفل فيما قبل المدرسة يعتمد تفكيره على الحدس والبداهة Intuition تمشي، لأنها في منطقة تتحرك، والحركة لا تكون صفة إلا للأحياء، وهو يتخيل مثنلا في قلم صغير وآخر طويل طفلا يسير مع أبيه، كما يتخيل في الحيوانات والطيور حياة أشبه بحياة الإنسان، فالطيور تتكلم والقطط تبكي، وهذه الأنسنة سمة تتبؤية تتصل بالثعر بصلة وثيقة، فالشعر تخييل، والتخييل تشخيص يتجاوز نقل الأشياء إلى أنفستها وإسقاط الذات عليها.

\section{الثكل}



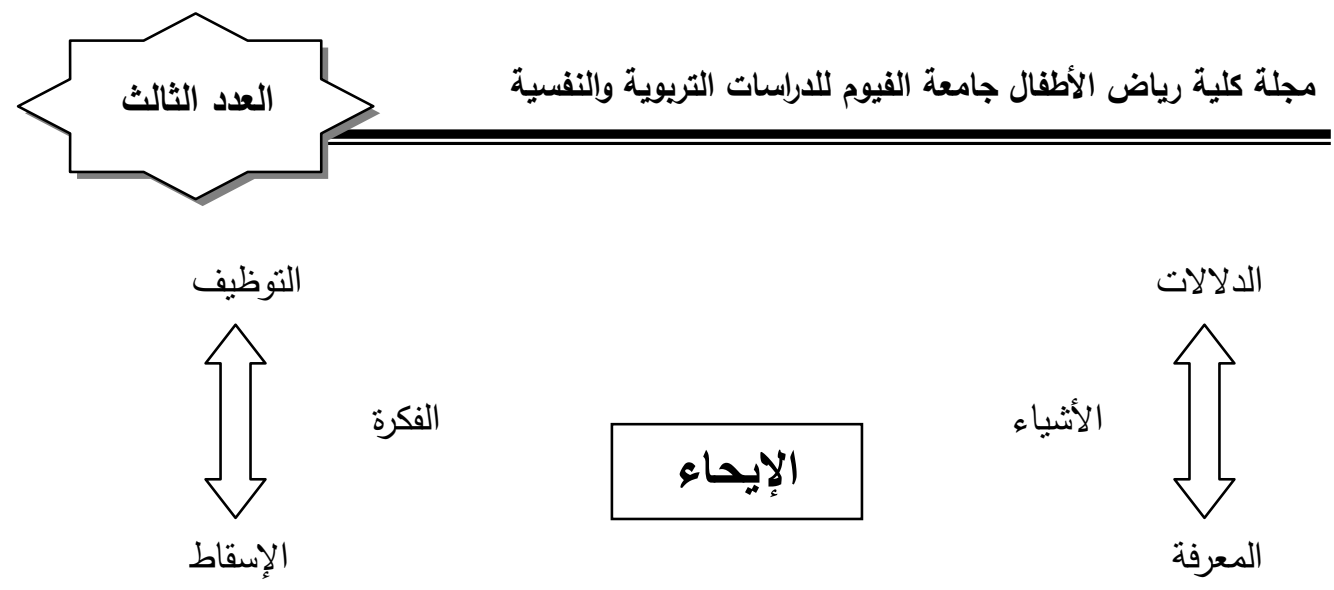

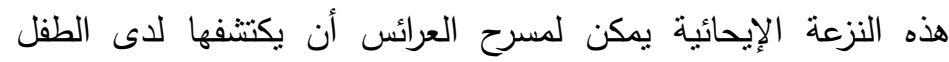

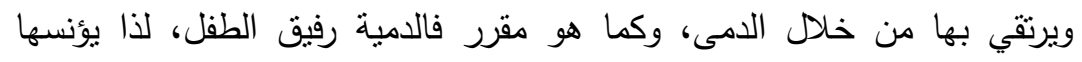
وينقبل منها ما لا يتقبله من البشر، ومن خلا هلال هذه الصلة يمكن إثباع ميله

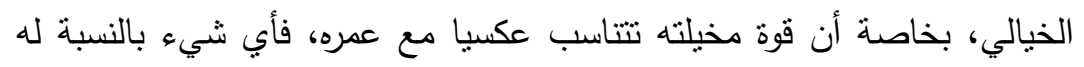

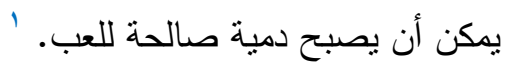

الثكل r 


$$
\text { د نــوال حيـفرى }
$$

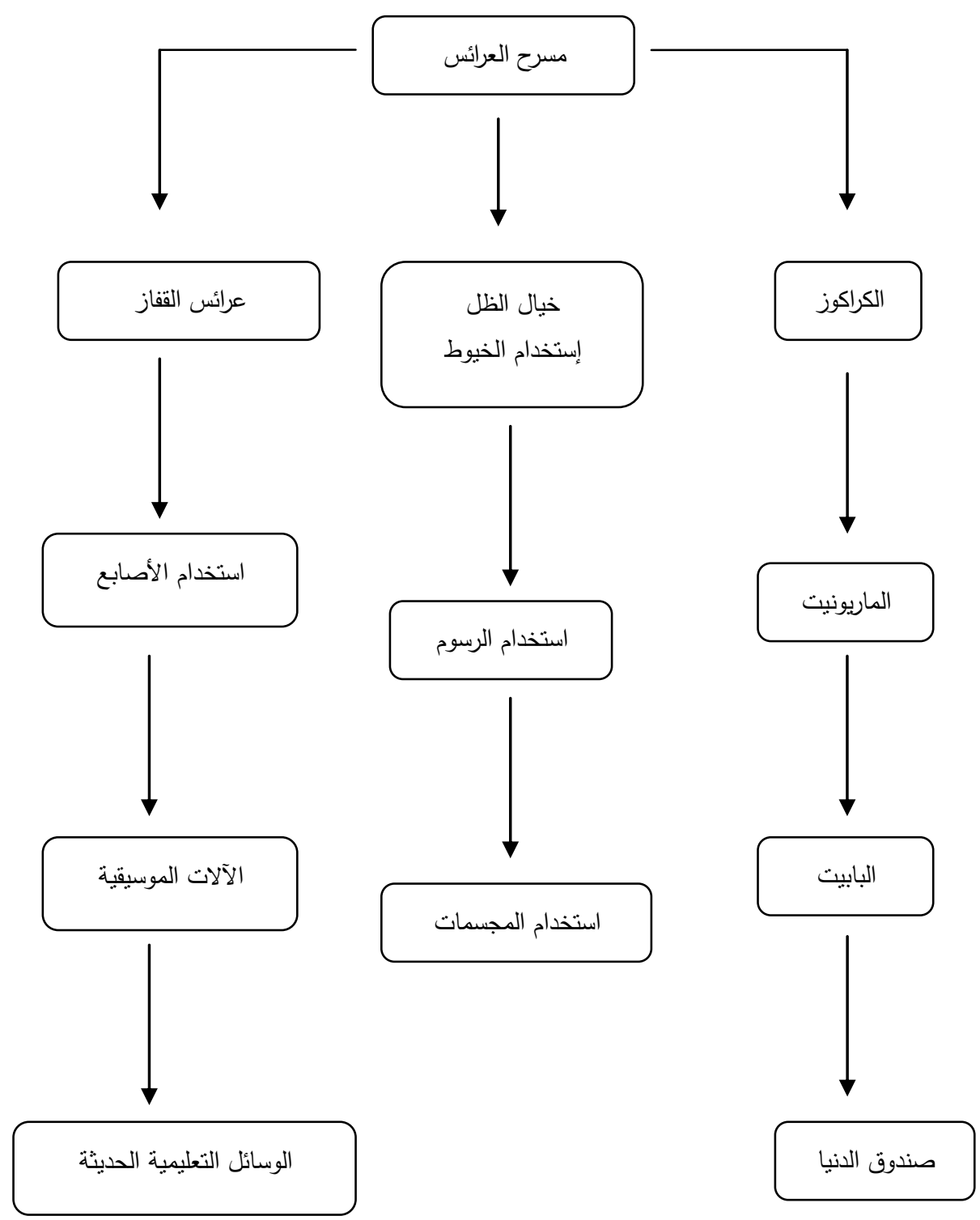

(1) - الثكل 

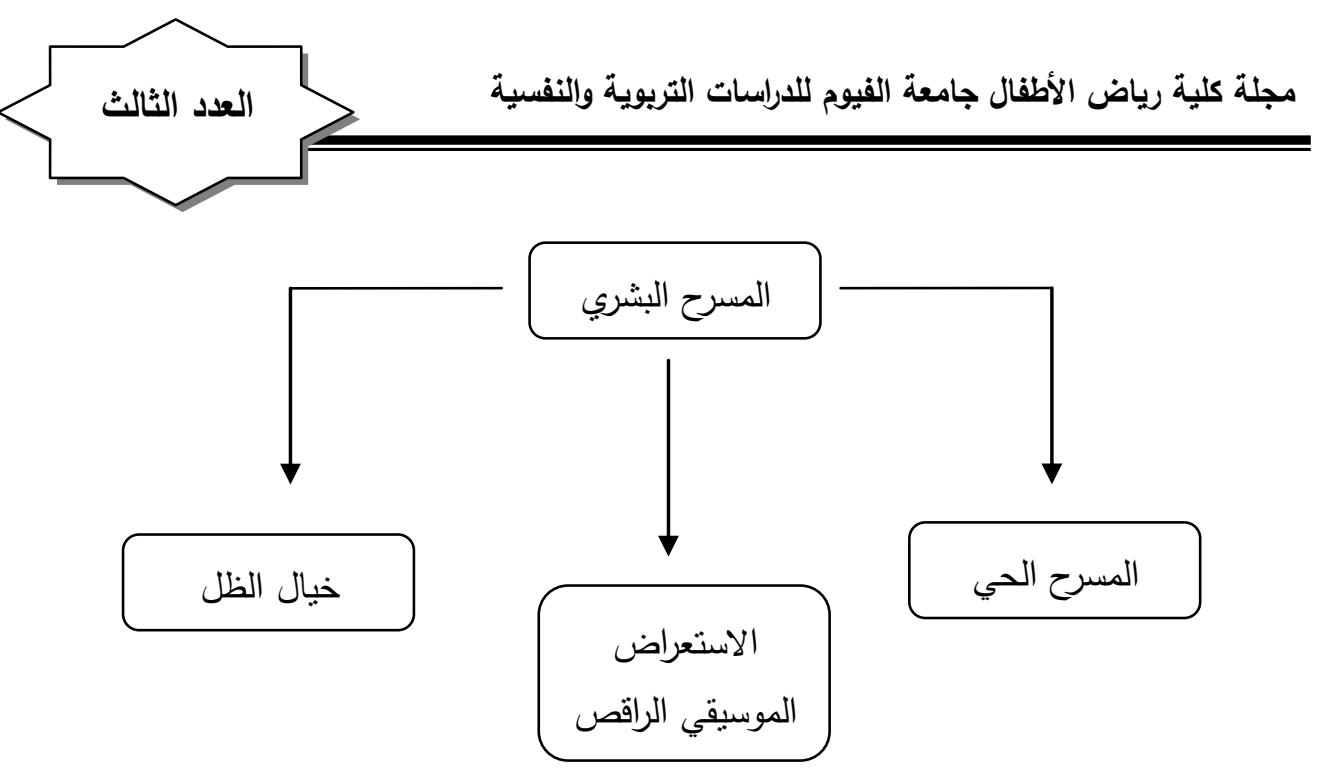

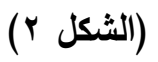

لذا نجد الدراما الموسيقية وإن كانت شبيهة في قصصها من حيث احتوائها

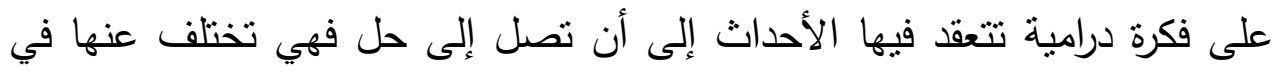
إمكانية تجاوز القاص حدود الزمان والمكان في حين يتحكم المؤلف الدرامي في اعتبارات الزمان والمكان والفعل الداعم للحدث العام للروئية الدرامية.

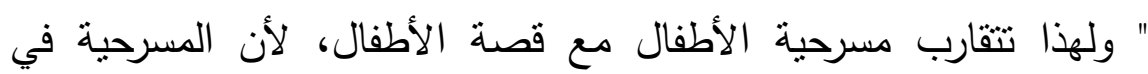
المألوف تحكى قصة بطريقة الحوار والحركة وهذا هو الجانب الذي لا يمكن التتازل

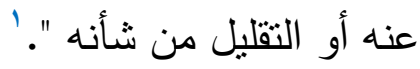
كما أن عالم الكتابة المسرحية للأطفال فن مستقل بذاته، متكامل بعناصره، يستمد خصوصيته من مميزات عالم الطفولة وخصائصها النفسية والاجتماعية والتي بهي تحتم مراعاتها أي عمل أدبي، أو تربوي يوجه للأطفال.

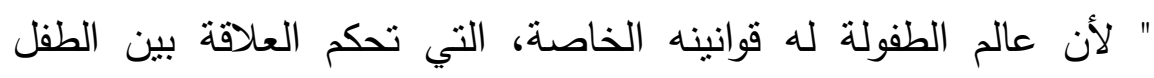
والقائمين من حوله والأثياء المحيطة به، وله طربقته في تصور الأمور، وحدوده في التصديق والتكذيب، وقدراته في التخيل... إنه عالم خاص، ولهذا يحتاج إلى دراية خاصة، وخبرة طويلة بالطفولة، عند الكتابة للطفل ". " فمن غير الحكمة استسهال الكتابة للأطفال لأنه أمر يتطلب من الكاتب لهنبه استخدام لغة غير معقدة أو مبهمة أو مستقاة من قاموس الأطفال اللغوي قوامها 


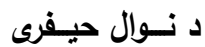

الكلمة الجميلة وعمادها الخيال وغرضها الإمتاع والتهذيب والتعلم والحرص على التيل إبراز القيم والتعاليم الأخلاقية والدينية.

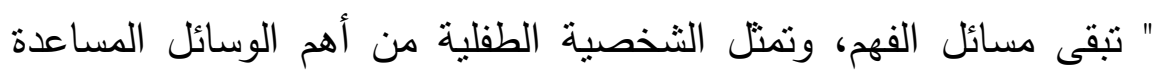

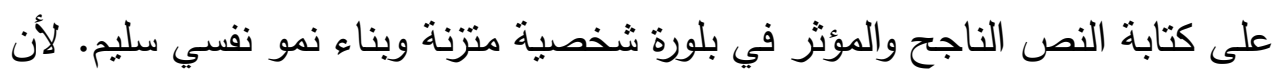

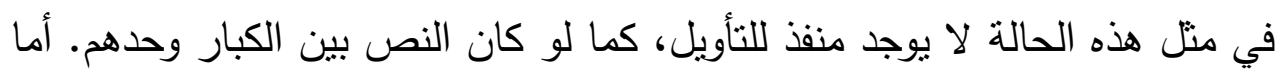

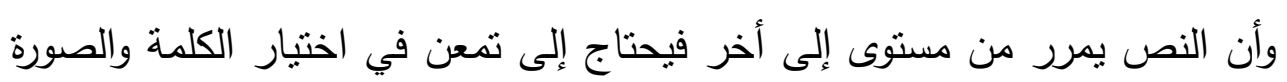

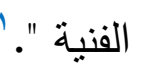

من هنا تبرز الصعوبات على المسافة التي تحدد العلاقة بين ما يعرض

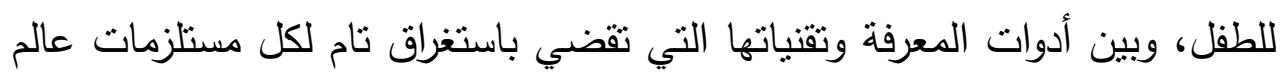

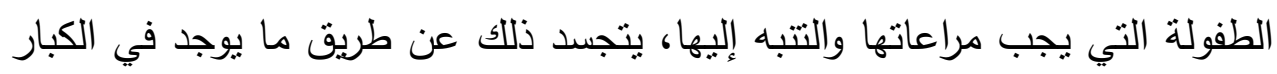
من عناصر مميزة تخص الطفل برتقون بواسطتها إلى مستوى الفهم الطفلي. إذ يطرح

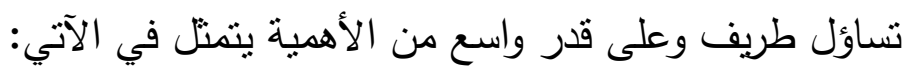

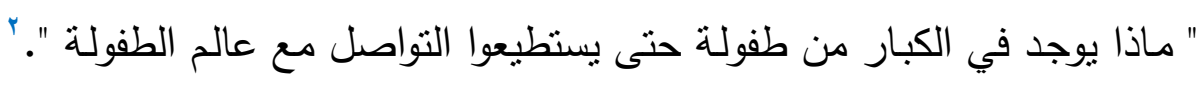

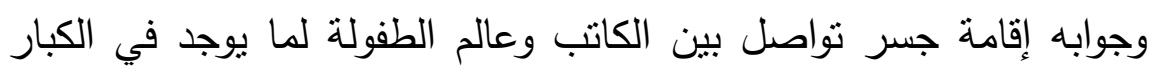

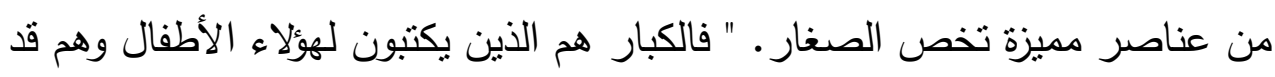
تجاوزوا هذه المرحلة مما يتطلب منهم ليس فقط استرجاع طفولتهم بملابساتها

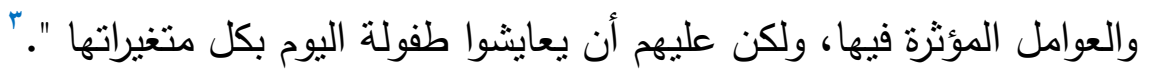

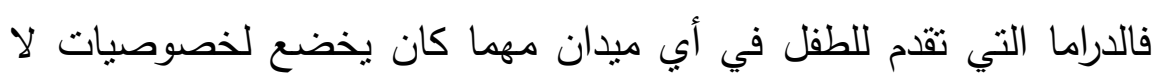
بخلو تحقيقها من الصعوبات التي تتعلق أساسا بالعلاقة النفسية بين الكاتب التبان وجمهور

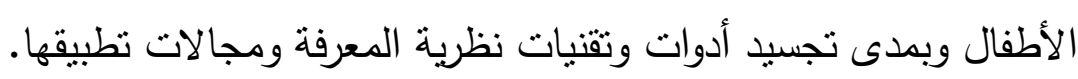

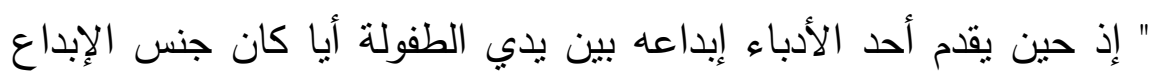

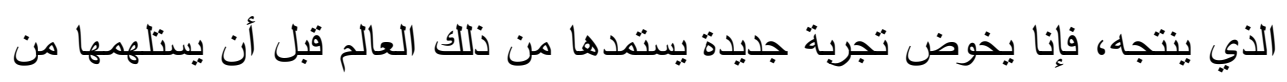

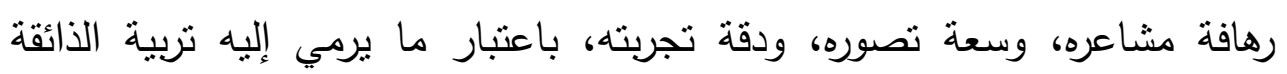

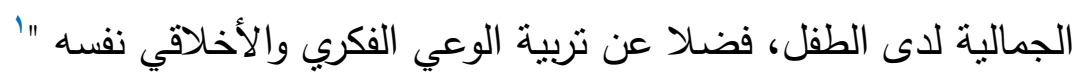


كما أن النص الأدبي الموجه للأطفال يتعين عليه ألا يخلو من عنصر الإثارة مع مراعاة القيم الدينية والسلوكية والاجتماعية والتركيز على العلوم المفيدة المختلفة بأسلوب شيق آخذين بنظر الاعتبار مختلف المراحل العمرية التي يمر بها

$$
\text { الطفل (الشكل r). }
$$

" فالاهتمام الذي يقوم به الكاتب من شأنه أن يساعد الطفل على اكتشاف

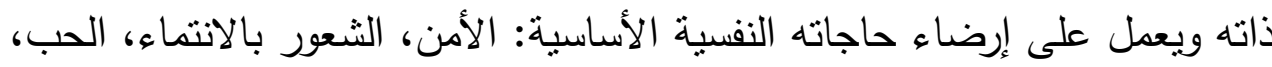

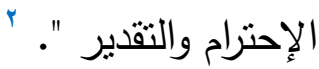

وإن كانت النصوص الأدبية والمسرحية تحديدا منها ما يفتقد إلى النظرة

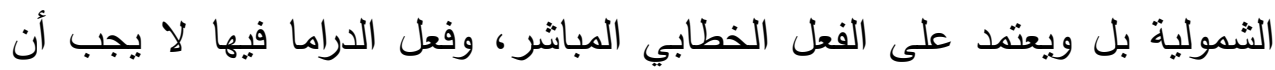
يكون خاليا من الجماليات والمؤثرات التي تجذب الطفل، إذ لا يمكن أن يتخيل الفرد

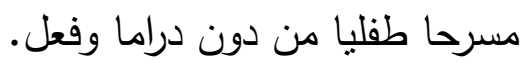

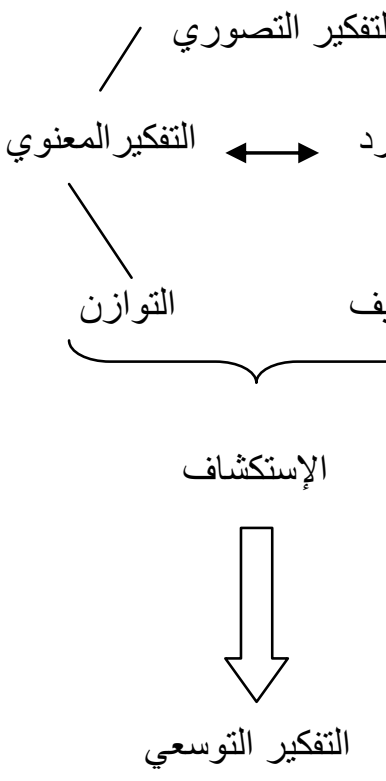

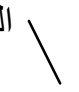

الموسيقى بين الدراما و الفعل 
فقوام النص الدرامي عناصر رئيسية ناظمة للكتابة الطفلية وهي بحاجة إلى تراكمية معرفية بهذا الفن إضافة إلى قراءات متوالية للوصول إلى المبادئ الأساسية

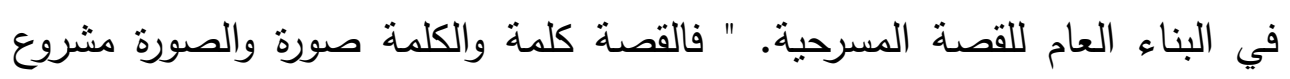
حباة ".

إن تقديم الحكايات في مسرح الطفل، وصياغتها بشكل مناسب فنيا وتربويا، هو تعلم الطفل مبادئ الخير والحق، والحكم الصحيح على الأحداث بالدرجة

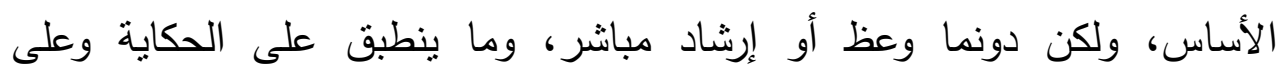

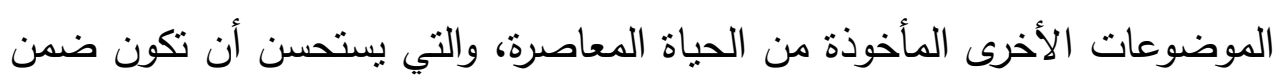
معرفة الطفل للواقع في جو من الغرابة الإثارة لثد انتباهه وتشويقه.

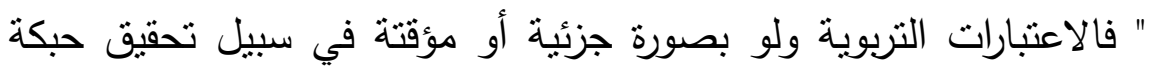

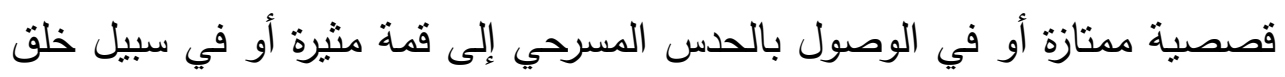

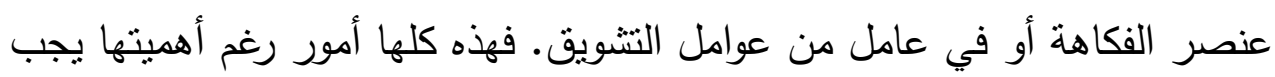

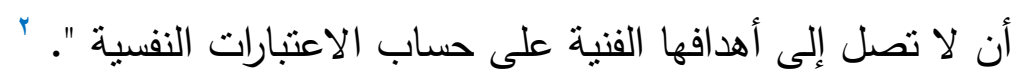

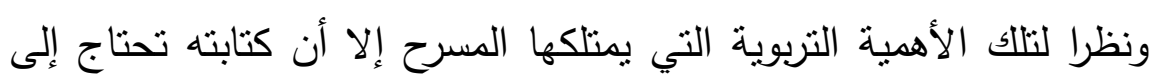

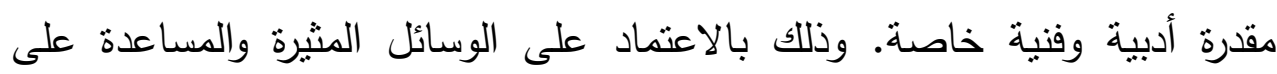
تشخيص الأحداث والأوضاع والعلاقات التي تتخذ منطلقا على استعمال اللغة. " فاللغة في العمل الأدبي لغة خاصة، ليست لمجرد التوصيل، ولكن: التوصيل والتصوير وإثارة الثعور والإقناع عن طريق التأثير في العاطفة (الإنفعال)". ذلك عندما تعرض مسرحية بأسلوب ناجح لتهذيب النفوس وتربية الوجدان

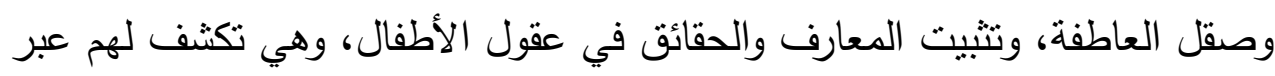
تجسيد المواقف والأحداث، عادات الناس وأخلاقهم وأساليب تعاملهم في الحياة اليومية، إضافة إلى أنها تدرب الأطفال على النطق الصحيح والكلام الواضح، مما ولإ

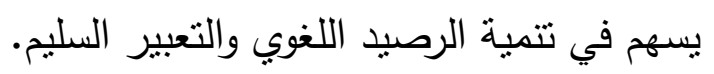




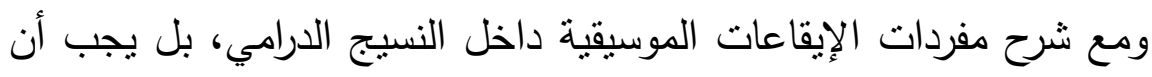
يعرف الطفل قيمة تلك الإيقاعات واستخدامها في الحياة ويعرف أيضا عن تللك الجماليات التي يمكن أن تصنفها تلك القصة الإيقاعية عن فكرة معنية . كما أن الحكاية جسد النص الدرامي الذي عن طريقه تتمو وتتقدم الأحداث

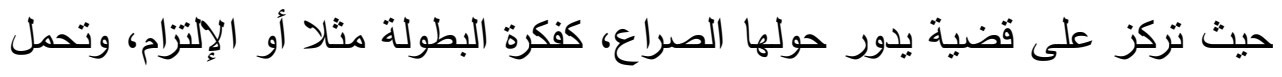

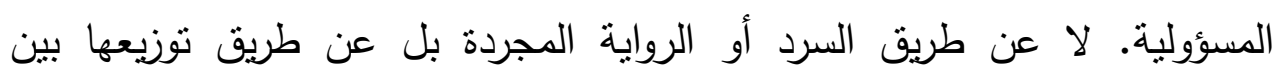
الثخصيات بدقة وترتيب وتدرج، بحيث يترتب اللاحق على السابق مما يجعل التسلسل بين الأحداث منطقيا. " فكم من أديب يتوقع أن الكتابة للأطفال تعني السهولة في اللغة ولكنني

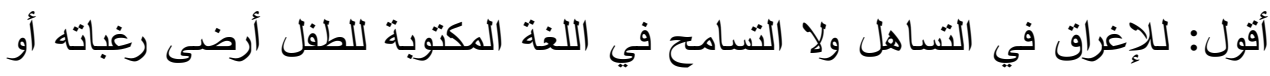
نمى لغته وثقافته ولا المباشرة في عرض القيم والأخلاق تخلصت من مبدأ التوجيه والإرشاد ما أدى إلى عجزها عن الارتقاء بمبادئه والسمو بسلوكه ". '

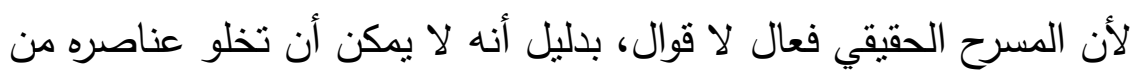

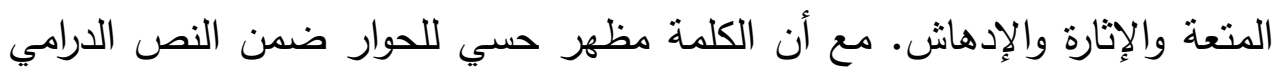
الذي يقوم بتصوير الأحداث وتتمية الصراع وتحريك المشاعر للوصول الإندارئ إلى النهاية.

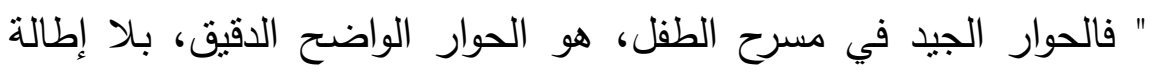

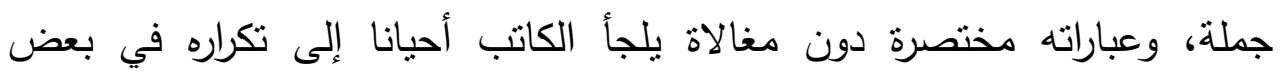
الأماكن، بقصد إمتاع القارئ والمتقرج، ومساعدته على الإندماج والتتبؤ بمصير

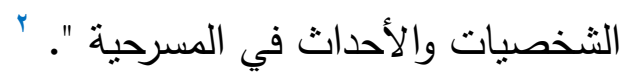

من جانب آخر تتوزع حواراته الموسيقية على ألسنة " شخصيات في المواقف المختلفة التي تختلف أجمل المسرحيات فيها طولا وقصرا باختلاف المواقف، كما تتفاوت فصاحتها تبعا لمستوى الثخصية وطبيعة الفكرة التي تعبر عنها. 


\section{د نــوال حيـفرى}

ومن الأحسن أن يركز الحوار على أمرين أساسين: ' / / التعبير عن الشخصيات: عمرها، مكانتها، ثقافتها، معاناتها. r/ الحركة: لأن قوة الحوار تكمن في حركته. كما أن حركية الحوار ظاهرية لأنها تسعى لترسيخ فكرة الحكاية المسرحية لكرية

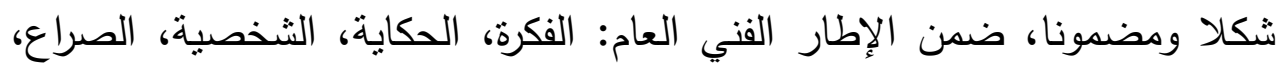
الأسلوب " لما يحمله من وظيفة مهمة تسهم في تصاعد الحدث والحفاظ على الإيقاع

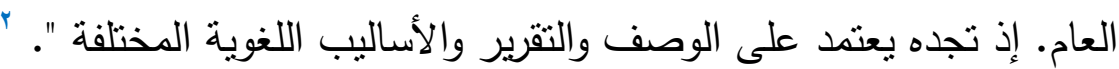

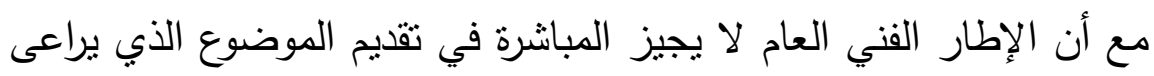
فيه نوازن الأجزاء في الحكاية المسرحية حتى تخضع لجاذبية النهاية القائمة على: عرض، تعقبد، حل إن وجد طبعا لأن:

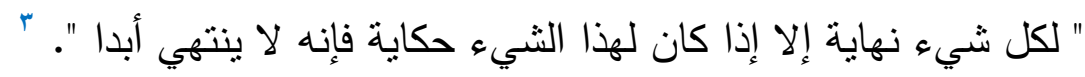

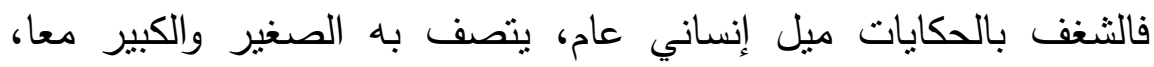

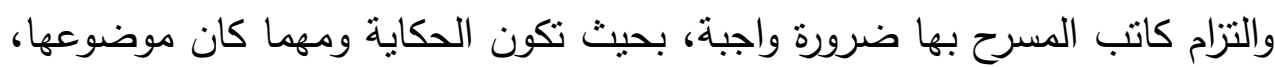
واضحة، بسيطة، مصاغة بإتقان، لتزيد من جذب إنتباه المتقرج الصغير • والحكايات

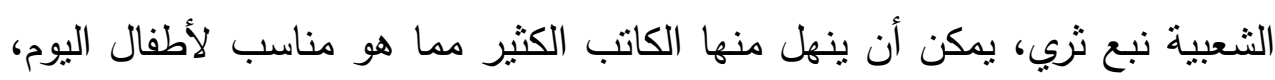

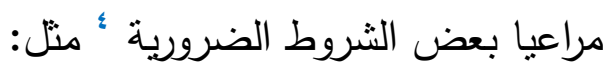

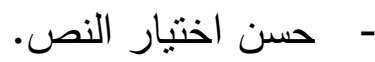
- موضوعات مرحة، خفيفة، تتمبز بالحركة. - أن - أنكون قريبة من الأطفال وحياتهم. -

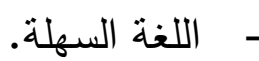
-

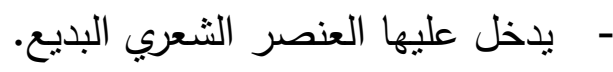
- الموسيقى الحالمة.

وذلك باستعمال الوسائل المثيرة والمساعدة على تشخيص الأحداث والأوضاع والعلاقات التي تتخذ منطلقا على استعمال اللغة مع مراعاة طبيعة النمو اللغوي عند 
الطفل بحيث نرتكز على الفهم أولا وعلى التكامل بين التدريب المباشر والاستعمال التلقائي ثانيا.

" فالمشاهد من المسرحيات متباين من الفئات العمرية من الأطفال لذا يجب أن تكون اللغة المستعملة تساعد الجميع لا على فهم محتوى النص فحسب بل من من لهن واستمتاعهم واندماجهم وانفعالهم بأحداثه وأفكاره حتى يحقق العمل الهدف المرجو منه

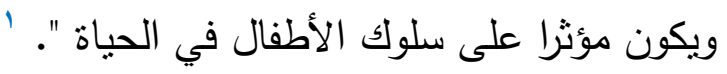
" وهذا يحتم الصياغة بلغة الحياة اليومية القائمة على ألفاظ وتراكيب مألوفة لماطية

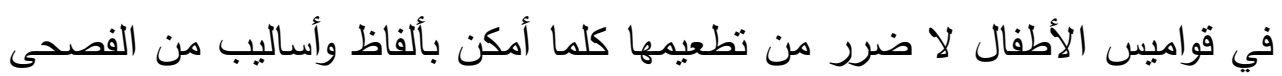

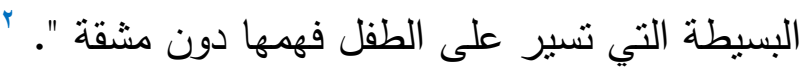
ليس لأن النص أداة توصيل فكرة وترفيه وممارسة على الركح بقدر ما هو فكر وعلم وتربية ورسالة أخلاقية. ومساعدة هذا المتلقي الصغير على معرفة قيمة

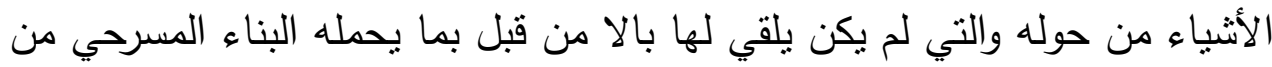

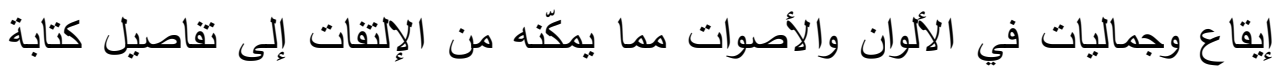
النصوص وما نتركه من وقع في النفس. (الثكل ع). 
الأدب إنفعال متخيل

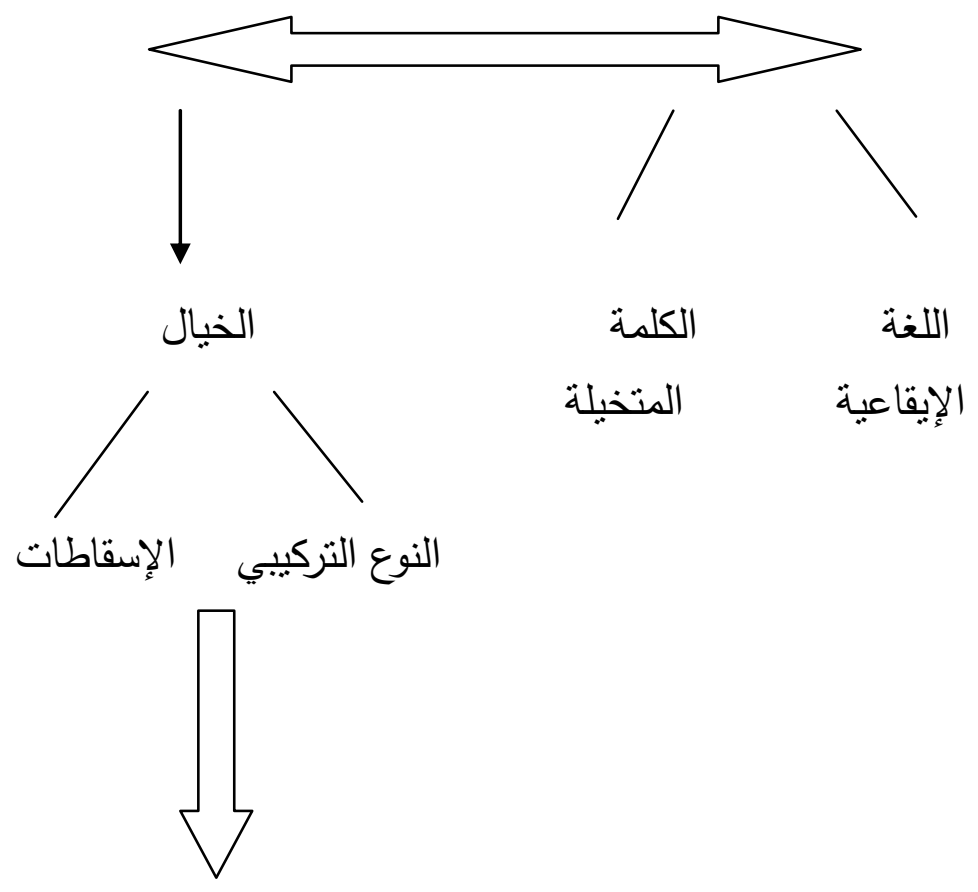

هواجس الأطفال

الفن

الإستعداد للذوق الإن

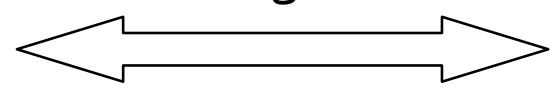

الشعور بالمتعة
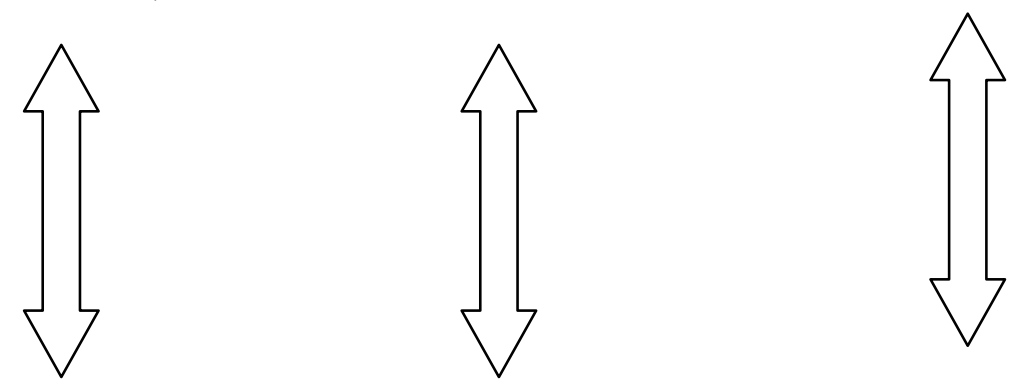

الإعجاب

التقدير

الإنتباه

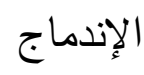

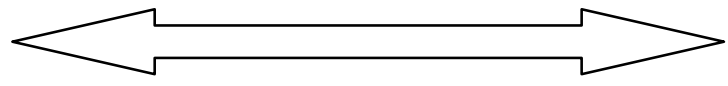

التعاطف

(الشكل \& ) (الشك) 
لذا تم التأكيد على أن الدراما وثثقة الارتباط بالتعليم أكثر من ارتباطها

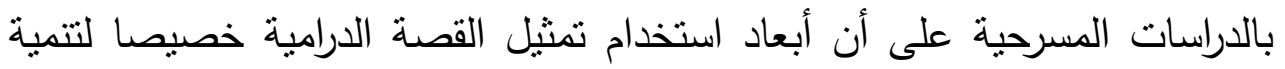

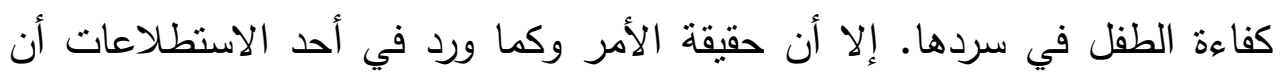

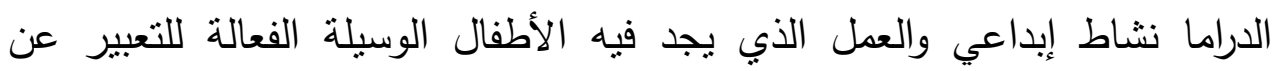
ذواتهم، ما لم يتدخل فيها الكبار، ويفتح الطريق أمامهم للوصول إلى اكتمال نموهم اليدم وشخصباتهم.

والأمر هنا كثثر الاهتمام والحث على " تقديم قصص حقيقية على الأطفال ذات نماذج خلفية عريقة ورفيعة... أي كتاب التدريب الذي يتعلم فيه الطفل كيف التهي

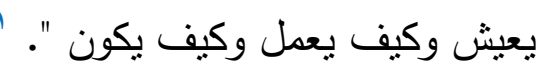

ويردف أصحاب هذا الرأي أن الدراما تتأى عما يسمى بالتمثيل المسرحي كونها ليست عبارة عن أثنياء يحفظها الطفل ثم يسمعها وليس هناك ممنل ومتفرج فقط بل نشاط إيهامي فيه لعب ونضال كما ورد في الأصل اليوناني، والحكاية فيها أهم جزء من العملية الأدبية برمتها التي يمكن توظيفها في مجال التربية والتعليم

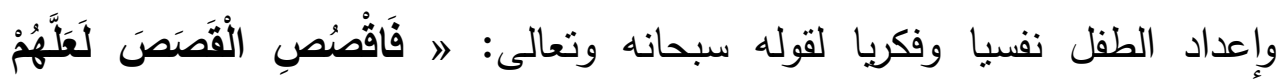

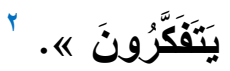

من جانب آخر يحصر التربويون فرقا بسيطا بين الاستعراض والدراما الموسيقية لشمولية الأولى وتخصيص الثانية، على أن الاستعراض ليس جنسا فرعيا بل لونا وعلى أن الحكاية ذات فعالية هامشية، كما تم تحديد الفرق الجوهري بينهما. 


$$
\text { د نــوال حيـفرى }
$$

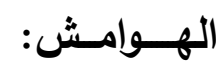

Voir Mark Twain. The writing of Mark Twain. Cambridge Schools Publishing. 2009. P 120

r - مادي لحسن. المسرح كتقنية بيداغوجية داخل المدرسة. مجلة التربية والتعليم.

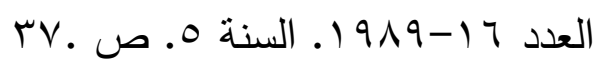

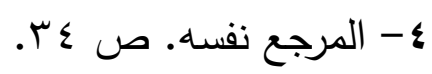

ه - عماد الدين إسماعيل. الأطفال مرآة المجتمع. مجلة عالم الفكر . الكويت. العدد

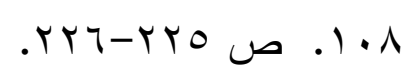

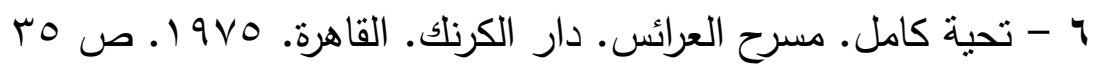
V - محد حسن عبد الله. قصص الأطفال ومسرحياتهم. دار قباء للطباعة والنشر .

$$
\begin{aligned}
& \text { Ar. . . . . } \\
& \text { A- أنظر نفسه. ص r }
\end{aligned}
$$

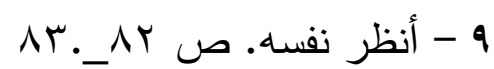

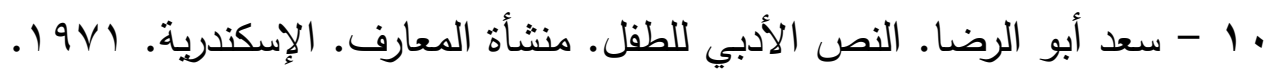

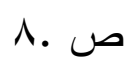

1 - سيسيليا ميرال. مشكلات الأدب الطفلي. ترجمة مها عرنوق. منشورات وزارة

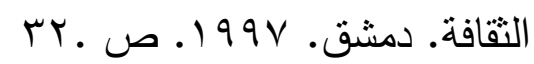

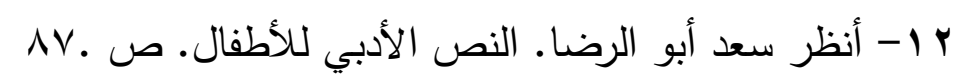

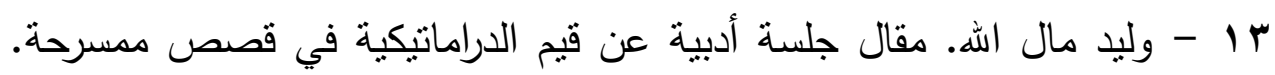
http//www.ulum.nl.htlm

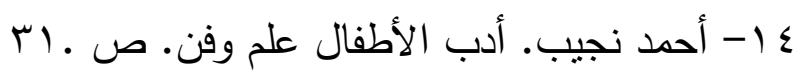

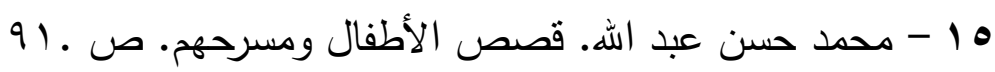

צ ا - مجلة الثقافة للجميع. حسين جمعة. أثز الأدب في عالم الطفولة.

$$
\text { ص ص مج }
$$

IV - سمير سلمون. مسرح الأطفال بين الواقع والطموح. مجلة الحياة المسرحية.

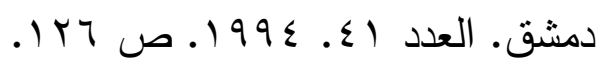

